\title{
Comparison of the effects of moderate and severe hypercapnic acidosis on ventilation-induced lung injury
}

Wanchao Yang ${ }^{1,2+}$, Ziyong Yue ${ }^{1,2 \dagger}$, Xiaoguang Cui ${ }^{1,2}$, Yueping Guo ${ }^{1,2}$, Lili Zhang ${ }^{1,2}$, Huacheng Zhou ${ }^{1,2}$ and Wenzhi Li ${ }^{1 *}$

\begin{abstract}
Background: We have proved that hypercapnic acidosis $\left(\mathrm{PaCO}_{2}\right.$ of $\left.80-100 \mathrm{mmHg}\right)$ protects against ventilator-induced lung injury in rats. However, there remains uncertainty regarding the appropriate target $\mathrm{PaCO}_{2}$ or if greater $\mathrm{CO}_{2}$ "doses" $\left(\mathrm{PaCO}_{2}>100 \mathrm{mmHg}\right)$ demonstrate this effect. We wished to determine whether severe acute hypercapnic acidosis can reduce stretch-induced injury, as well as the role of nuclear factor-KB (NF-kB) in the effects of acute hypercapnic acidosis.

Methods: Fifty-four rats were ventilated for 4 hours with a pressure-controlled ventilation mode set at a peak inspiratory pressure (PIP) of $30 \mathrm{cmH}_{2} \mathrm{O}$. A gas mixture of carbon dioxide with oxygen $\left(\mathrm{FiCO}_{2}=4-5 \%, \mathrm{FiCO}_{2}=11-12 \%\right.$ or $\mathrm{FiCO}_{2}=$ 16-17\%; $\mathrm{FiO}_{2}=0.7$; balance $\mathrm{N}_{2}$ ) was immediately administered to maintain the target $\mathrm{PaCO}_{2}$ in the $\mathrm{NC}\left(\mathrm{a} \mathrm{PaCO}_{2}\right.$ of 35-45 mmHg), MHA (a $\mathrm{PaCO}_{2}$ of 80-100 mmHg) and SHA (a $\mathrm{PaCO}_{2}$ of $130-150 \mathrm{mmHg}$ ) groups. Nine normal or non-ventilated rats served as controls. The hemodynamics, gas exchange and inflammatory parameters were measured. The role of NF-KB pathway in hypercapnic acidosis-mediated protection from high-pressure stretch injury was then determined.

Results: In the NC group, high-pressure ventilation resulted in a decrease in $\mathrm{PaO}_{2} / \mathrm{FiO}_{2}$ from 415.6 (37.1) $\mathrm{mmHg}$ to 179.1 (23.5) $\mathrm{mmHg}(p<0.001)$, but improved by MHA $(379.9 \pm 34.5 \mathrm{mmHg})$ and SHA $(298.6 \pm 35.3 \mathrm{mmHg})$. The lung injury score in the SHA group $(7.8 \pm 1.6)$ was lower than the NC group $(11.8 \pm 2.3, \mathrm{P}<0.05)$ but was higher than the MHA group $(4.4 \pm 1.3, \mathrm{P}<0.05)$. Compared with the NC group, after $4 \mathrm{~h}$ of high pressure ventilation, the MHA and SHA groups had decreases in MPO activity of $67 \%$ and $33 \%$, respectively, and also declined the levels of TNF-a (58\% versus $72 \%$ ) and MIP-2 (76\% versus 60\%) in the BALF. Additionally, both hypercapnic acidosis groups reduced stretch-induced NF-kB activation ( $p<0.05)$ and significantly decreased lung ICAM-1 expression $(p<0.05)$.
\end{abstract}

Conclusions: Moderate hypercapnic acidosis $\left(\mathrm{PaCO}_{2}\right.$ maintained at $\left.80-100 \mathrm{mmHg}\right)$ has a greater protective effect on high-pressure ventilation-induced inflammatory injury. The potential mechanisms may involve alterations in NF-KB activity.

Keywords: Hypercapnic acidosis, Ventilation-induced lung injury, Nuclear factor kappa B, Cytokines

\section{Background}

Mechanical ventilation with high pressure or high volume has been reported that can induce lung injury as the typical of hyaline membrane formation, pulmonary edema, and deterioration in oxygenation [1,2]. Dreyfuss et al. reported that ventilation with $45 \mathrm{~cm} \mathrm{H}_{2} \mathrm{O}$ peak inspiratory pressure

\footnotetext{
*Correspondence: Wenzhili9@126.com

${ }^{+}$Equal contributors

'Department of Anesthesiology, Second Affiliated Hospital of Harbin Medical University; Anesthesiology Key Laboratory, Harbin Medical University, Harbin 150086, China

Full list of author information is available at the end of the article
}

(PIP) resulted in pathophysiological changes in the lungs, such as the destruction of epithelial lining and basement membrane [1]. Recent researches have focused on trying to decrease mortality by reducing ventilator-induced lung injury (VILI) [3,4]. These attempts impose restrictions on the tidal volume $\left(\mathrm{V}_{\mathrm{T}}\right)$ and inflation pressure and may lead to hypercapnic acidosis (HA). Studies have also found that hypercapnic acidosis can directly attenuate experimental acute lung injuries induced by ischemia-reperfusion [5], free radicals [6], endotoxin $[7,8]$, systemic sepsis $[9,10]$, and VILI both ex vivo [11,12] and in vivo [12-14]. These studies 
indicated that hypercapnic acidosis may reduce lung injury, with the mechanisms hypothesized to function through anti-inflammatory and lung surfactant effects [15] as well as a reduction in $\mathrm{NO}$ [16] and attenuation of the nuclear factor kappa B (NF-kB) pathway [12]. NF- $\mathrm{kB}$ is a key transcriptional factor that modulates the gene expression of various pro-inflammatory cytokines and adhesion molecules [17-19]. More recent studies have demonstrated that the effects of HA-both beneficial and deleterious-may be mediated at least in part via the inhibition of NF- $\mathrm{kB}$ activity [12,20].

In our previous study, the protective effects of hypercapnic acidosis associated with a particular level of $\mathrm{PaCO}_{2}$ have been demonstrated in moderate-range hypercapnic acidosis $\left(\mathrm{PaCO}_{2}\right.$ maintained at $\left.80-100 \mathrm{mmHg}\right)$ [21]. Although the dose-response characteristics of hypercapnic acidosis have previously been demonstrated in the setting of ischemia-reperfusion injury [22], there remains uncertainty regarding the appropriate target $\mathrm{PaCO}_{2}$ in the setting of VILI in vivo. Our previous results from an in vivo model of cerebral ischemia showed that a $\mathrm{PaCO}_{2}$ of $100 \mathrm{mmHg}$ may be the upper limit of the neuroprotective range of hypercapnia [23]. This evidence indicates that higher doses of $\mathrm{PaCO}_{2}$ likely had adverse effects on neurologic outcomes in a rat cerebral ischemia model. Whether this phenomenon is similar to that in high-pressure ventilationinduced lung injury is less clear.

We hypothesized that greater $\mathrm{CO}_{2}$ "doses" $\left(\mathrm{PaCO}_{2}>\right.$ $100 \mathrm{mmHg}$ ) in rats receiving high-pressure ventilation (HPV) were associated with decreased protective effects of HA in reducing pulmonary inflammatory injury. We sought: (1) to compare the effects of moderate hypercapnic acidosis $\left(\mathrm{PaCO}_{2}\right.$ of $\left.80-100 \mathrm{mmHg}\right)$ and severe hypercapnic acidosis $\left(\mathrm{PaCO}_{2}\right.$ of $\left.130-150 \mathrm{mmHg}\right)$ on HPV-induced inflammatory injury and (2) to elucidate the role of the $\mathrm{NF}-\mathrm{kB}$ pathway in this process.

\section{Methods}

\section{Experimental protocol}

The experimental protocols were approved by the Institutional Animal Care and Use Committee of Harbin Medical University, and conducted in compliance with the animal-use guidelines (SYXK (Hei) 2006-033). Seventy-two adult Wistar rats (weight 250-300 g) were anesthetized with an intraperitoneal injection of $30 \mathrm{mg} / \mathrm{kg}$ of pentobarbital sodium. The internal carotid artery was cannulated with a 20-gauge catheter to aspirate blood for blood gas analysis and arterial pressure monitoring. The rectal temperature was maintained at $37.0-38.5^{\circ} \mathrm{C}$. Mechanical ventilation delivered via tracheostomy was initiated in the pressure-controlled mode (Kent Scientific Ventilator-Dual Mode, USA) with $15 \mathrm{cmH}_{2} \mathrm{O}$ PIP, a positive end-expiratory pressure (PEEP) of $2 \mathrm{cmH}_{2} \mathrm{O}$, a frequency of 30 breaths/min to maintain the $\mathrm{PaCO}_{2}$ at
35-45 mmHg, an inspiration-to-expiration (I:E) ratio of 1:2, and an inhaled oxygen fraction $\left(\mathrm{FiO}_{2}\right)$ of 0.7 for $15 \mathrm{~min}$, after which baseline data were collected.

Prior to randomization, the following values needed to be stable: $\mathrm{PaO}_{2} / \mathrm{FiO}_{2}>300 \mathrm{mmHg}, \mathrm{PaCO}_{2} 30-45 \mathrm{mmHg}$, and $\mathrm{HCO}_{3}^{-}>20 \mathrm{mmol} \cdot \mathrm{L}^{-1}$. If any parameter was not fulfilled, the animals were excluded from the protocol and further data analysis.

\section{Experimental groups}

Seventy two rats were randomly assigned to 8 blocks of 9 animals each, with random numbers generated by SPSS (version 13.01S; Beijing Stats Data Mining Co. Ltd, Beijing, China). Among them, two blocks were randomly assigned to the sham group (anaesthetized and nonventilated rats) and NV group (ventilated with $\mathrm{PIP}=15$ $\mathrm{cmH}_{2} \mathrm{O}$ and inhaled $\mathrm{FiO}_{2}$ of 0.7 for $4 \mathrm{~h}$ ) served as controls for assessing the expression of NF- $\mathrm{kB}$ p 65 protein and the inflammatory mediators in the lung. The left 6 blocks were assigned to three groups through merging two blocks of rats randomly, and including the Normocapnia (NC) group $\left(\mathrm{PaCO}_{2}=35-45 \mathrm{mmHg}, \mathrm{n}=18\right)$, $\mathrm{PaCO}_{2}$ was maintained in the normal range through inhaling the gas mixture $\left(\mathrm{FiO}_{2} 0.7, \mathrm{FiCO}_{2} 4-5 \%\right.$, balance $\mathrm{N}_{2}$ ); the Moderate Hypercapnic Acidosis (MHA) group $\left(\mathrm{PaCO}_{2}=80-100 \mathrm{mmHg}, \mathrm{n}=18\right), \mathrm{PaCO}_{2}$ was maintained through inhaling the gas mixture $\left(\mathrm{FiO}_{2} 0.7, \mathrm{FiCO}_{2}\right.$ 11$12 \%$, balance $\mathrm{N}_{2}$ ); and the Severe Hypercapnic Acidosis (SHA) group $\left(\mathrm{PaCO}_{2}=130-150 \mathrm{mmHg}, \mathrm{n}=18\right), \mathrm{PaCO}_{2}$ was maintained through inhaling the gas mixture $\left(\mathrm{FiO}_{2}\right.$ $0.7, \mathrm{FiCO}_{2} 16-17 \%$, balance $\mathrm{N}_{2}$ ). The rats in the three groups were ventilated for $4 \mathrm{~h}$ in the supine position with a PIP of $30 \mathrm{cmH}_{2} \mathrm{O}$ via the pressure-controlled mode (inspiratory time $=0.7 \mathrm{~s}$; PEEP $=2 \mathrm{cmH}_{2} \mathrm{O}$ and respiratory rate $=30$ breaths $/ \mathrm{min}$ ). For all rats, anesthesia was maintained with sodium pentobarbital $\left(2-4 \mathrm{mg} \cdot \mathrm{kg}^{-1} \cdot \mathrm{hr}^{-1}\right)$ and pancuronium bromide $\left(0.03-0.07 \mathrm{mg} \cdot \mathrm{kg}^{-1} \cdot \mathrm{hr}^{-1}\right)$. Throughout the experiment, frequent checks were made to ensure that the animals were adequately anesthetized. This was performed by applying a painful stimulus to a paw and observing blood pressure responses. Lactated Ringer's solution was infused i.v. at $10 \mathrm{ml} \cdot \mathrm{kg}^{-1} \cdot \mathrm{hr}^{-1}$ to compensate for blood sampling.

\section{Measurement of physiologic indices}

In all experimental series, the systemic mean blood pressure (MAP) and heart rate (HR) were recorded at baseline, initiation of test conditions, and at 1-hour intervals thereafter. These were measured using an MP150 Workstation and analyzed using the AcqKnowledge software (BIOPAC Systems, Inc., Santa Barbara, CA) according to the manufacturer's specifications. Tidal volumes $\left(\mathrm{V}_{\mathrm{T}}\right)$ were determined every 60 min with a VT Plus HF Gas Flow Analyzer (Fluke Corporation, USA). Inhaled and exhaled 
$\mathrm{CO}_{2}$ and $\mathrm{O}_{2}$ were tested using a gas monitor (DATEX Instrumentarium, Helsinki, Finland). Arterial blood samples were taken at baseline and every $60 \mathrm{~min}$ after randomization in each series, and blood gas analysis was performed (Rapidlab 248, Bayer Company, USA).

\section{Assay of inflammatory mediators in BALF and myeloperoxidase activity in lungs}

At the end of the experiment, animals were exsanguinated, and the heart and lungs were dissected from the thorax. The right lobe bronchus was lavaged using sterile saline with $5 \mathrm{ml}$ of saline $\left(0.9 \%, 4^{\circ} \mathrm{C}\right)$ by three separate washes, and $4 \mathrm{ml}$ of bronchoalveolar lavage fluid (BALF) was collected. A $1.0 \mathrm{ml}$ aliquot was used for cell counts. The remaining fluid was centrifuged $\left(300 \times \mathrm{g}\right.$ at $4^{\circ} \mathrm{C}$ for $10 \mathrm{~min}$ ), and the cell-free supernatant was divided into two 1 -ml aliquots. One aliquot was snap-frozen in liquid nitrogen and stored at $-80^{\circ} \mathrm{C}$ for subsequent analysis of tumor necrosis factor (TNF-a), interleukin (IL)-1 $\beta$, and macrophage inflammatory protein-2 (MIP-2) using a commercial enzyme-linked immunosorbent assay kits (R\&D Systems, Minneapolis, MN, USA). The remaining aliquot was frozen at $-20^{\circ} \mathrm{C}$ for a measurement of the total protein concentration (BCA; Pierce, Rockford, IL). The right lobe of the lung was stored at $-80^{\circ} \mathrm{C}$ and was later ground into homogenate to measure myeloperoxidase (MPO) activity using a kit (Jiancheng Bio-Technology, Nanjing, China) and a spectrophotometer. One unit of MPO was defined as the quantity that degraded $1.0 \mathrm{mmol}$ of peroxide per minute at $37^{\circ} \mathrm{C}$. The results were expressed as units per gram of wet lung tissue (U/g).

\section{Histology and immunohistochemistry}

A $1 \mathrm{~cm}^{3}$ core sample was extracted from the visually estimated center of the left upper lobe of the lung, fixed in $4 \%$ buffered formalin and embedded in paraffin. The samples were then sectioned, stained with hematoxylin and eosin, and examined by a pathologist who was blinded to the protocol. The evaluation was based on the following criteria as described previously [24]: (1) neutrophil infiltration; (2) interstitial edema; (3) alveolar edema; (4) hyaline membrane formation. Each criterion was scored on a semiquantitative scale of $0-4$, where $0=$ normal, $1=$ minimal change, $2=$ mild change, $3=$ moderate change and $4=$ severe change. An overall histological score was calculated by totaling the scores for criteria 1 through 4 . The left lower lobe of the lung was used to determine the wet: dry weight ratio (WW: DW) of the lung.

The expression of intercellular adhesion molecule-1 (ICAM-1) and NF- $\mathrm{kB}$ in lung sections was measured by immunohistochemical staining with an ICAM-1 detection kit (Zhongshan Golden Bridge Biotechnology, Beijing, China) and an NF-kB p65 antibody (Santa Cruz Biotechnology, Inc., Santa Cruz, CA). Specific labeling was detected with an Elite $A B C$ peroxidase kit and diaminobenzidine (DAB) (Zhongshan Golden Bridge Biotechnology). Briefly, slides were systematically scanned at a lower magnification to define the lung injury by evaluating H\&E-stained slides along with consecutive immunohistochemistry-stained slides. Eight to ten representative digital images were acquired from each slide using a $40 \times$ objective. Brown granules were quantified as positively stained cells or nuclei in each high-powered field (400 x magnification). The results were expressed as the percentage of positively stained cells or ratio of nuclei to total cells from 8-10 digital images per animal and four animals per group.

\section{Determination of NF-KB and IKB- $\alpha$ concentration}

Tissues were homogenized in RIPA buffer and lysed for $30 \mathrm{~min}$ on ice. Samples were then sonicated, vortexed and centrifuged at $12,000 \times \mathrm{g}$ for $20 \mathrm{~min}$ at $4^{\circ} \mathrm{C}$. Nuclear and cytoplasmic fractionation was performed using an $\mathrm{EZ}$ nuclei isolation kit (Applygen Technologies Inc.; China). Nuclear P65 concentrations and cytoplasmic IкB- $\alpha$ concentrations were determined using western blot analysis. Briefly, the supernatants were collected and separated using SDS-polyacrylamide gels, blotted onto membranes and incubated with the primary rabbit polyclonal anti-NF-kB p65 antibody, rabbit polyclonal anti-I-kappaB Kinase (ІКB)- $\alpha$ antibody or ICAM-1 (M-19) antibody (Santa Cruz Biotechnology Inc., USA). Signals on the membranes were detected with an Odyssey Infrared Imaging System (LI-COR Bioscience, USA). The level of measured materials was normalized to the level of $\beta$-actin. Total lung NF- $\mathrm{BB}$ activity was determined using an activated NF-kB ELISA assay kit (TransAM NF- $\kappa B$; Active Motif, Carlsbad, CA). In this kit, an oligonucleotide containing an NF- $\mathrm{kB}$ consensus site (5'-GGGACTTTCC-3') was absorbed onto polystyrene microwells.

\section{Statistical analysis}

All data are presented as mean (SD). Statistical analyses were performed using SPSS (version 13.01S; Beijing Stats Data Mining Co. Ltd, Beijing, China). Power calculations were performed prior to the commencement of the study. A sample size of 8 in each block will be sufficient to detect a difference of $0.1 \mathrm{U} / \mathrm{g}$ in $\mathrm{MPO}$ between the treatment and the control groups assuming a standard deviation of $0.1 \mathrm{U} / \mathrm{g}$ as reported in this population, at $80 \%$ power and $5 \%$ level of significance. This number has been increased to 9 per block (total of 72) to allow for a predicted drop-out from treatment of around $10 \%$. Group comparisons were evaluated with a one-way ANOVA followed by the Student-Newman-Keuls (SNK) test for multiple comparisons. MAP, $\mathrm{HR}, \mathrm{V}_{\mathrm{T}}, \mathrm{pH}, \mathrm{PaCO}_{2}$ and $\mathrm{PaO}_{2} / \mathrm{FiO}_{2}$ levels were evaluated by repeated measures ANOVA with time (five levels: baseline, at 1 hour, 2 hours, 
3 hours and 4 hours after ventilation) as a within-subject factor and group (three levels: NC, MHA and SHA) as a between-subject factor. Overall significant differences in time, group and interaction between time and group were determined by a two-tailed $\mathrm{p}<0.05$.

\section{Results}

Seven rats (two from each HPV group and one from NV group) that died before the $3 \mathrm{~h}$ mark were excluded from the study because of progressive hypotension. Forty-eight rats in HPV groups and eight rats in NV group survived the $4 \mathrm{~h}$ ventilation protocol and were included in the subsequent data analysis. The physiological characteristics of the NC, MHA and SHA groups were similar at baseline.

Hemodynamic variables and arterial blood gas analysis The hemodynamics induced by the VILI process and management are shown in Table $1 . T^{T} V_{T}$ decreased gradually during the last $2 \mathrm{~h}$ period compared with the first $2 \mathrm{~h}$ period in the NC and SHA groups, but this effect was not observed in the MHA group (Table 1).

The results of the blood gas analysis are shown in Table 1, including the $\mathrm{PaO}_{2} / \mathrm{FiO}_{2}, \mathrm{PaCO}_{2}$ and $\mathrm{pH}$ values. In the $\mathrm{NC}$ group, high-pressure ventilation resulted in a decrease in $\mathrm{PaO}_{2} / \mathrm{FiO}_{2}$ from 415.6 (37.1) mmHg to 179.1 (23.5) $\mathrm{mmHg}(\mathrm{p}<0.001)$. This gradually increased and was significantly improved in both hypercapnic acidosis groups $(\mathrm{p}<0.05)$, but the values of $\mathrm{PaO}_{2} / \mathrm{FiO}_{2}$ in the MHA group were significantly higher than those in the SHA group at the end of the protocol $(\mathrm{p}<0.05)$.

Pulmonary permeability changes and neutrophil counts As shown in Figure 1, BALF protein concentrations and the WW: DW in both hypercapnic acidosis groups were significantly reduced compared with the $\mathrm{NC}$ group $(\mathrm{p}<0.05)$. Inhalation of $\mathrm{CO}_{2}$ during VILI

Table 1 Hemodynamic parameters and gas exchange at different timepoints for each group

\begin{tabular}{|c|c|c|c|c|c|}
\hline & Baseline & $1 \mathrm{~h}$ & $2 \mathrm{~h}$ & $3 \mathrm{~h}$ & $4 \mathrm{~h}$ \\
\hline \multicolumn{6}{|c|}{$\mathrm{MAP}(\mathrm{mmHg})$} \\
\hline NC & $126 \pm 8$ & $124 \pm 10$ & $119 \pm 12$ & $113 \pm 12^{*}$ & $90 \pm 24^{*}$ \\
\hline MHA & $122 \pm 13$ & $130 \pm 12$ & $134 \pm 9^{* \dagger}$ & $135 \pm 12^{* \dagger}$ & $127 \pm 12^{\dagger}$ \\
\hline SHA & $127 \pm 15$ & $137 \pm 7^{*{ }^{\dagger}}$ & $134 \pm 7^{\dagger}$ & $123 \pm 12^{\dagger \#}$ & $113 \pm 17^{*+\#}$ \\
\hline \multicolumn{6}{|c|}{$\mathrm{HR}(1 / \mathrm{min})$} \\
\hline NC & $347 \pm 26$ & $324 \pm 31$ & $295 \pm 38^{*}$ & $283 \pm 39^{*}$ & $258 \pm 28^{*}$ \\
\hline MHA & $362 \pm 15$ & $323 \pm 17$ & $294 \pm 23^{*}$ & $283 \pm 20^{*}$ & $270 \pm 19^{*}$ \\
\hline $\mathrm{SHA}$ & $347 \pm 24$ & $284 \pm 29^{* \# \#}$ & $258 \pm 40^{* \# \#}$ & $243 \pm 38^{* \star \#}$ & $224 \pm 35^{* \dagger \#}$ \\
\hline \multicolumn{6}{|l|}{$\mathrm{V}_{\mathrm{T}}(\mathrm{ml})$} \\
\hline NC & $2.4 \pm 0.3$ & $9.5 \pm 0.9$ & $9.2 \pm 0.7$ & $8.4 \pm 1.0$ & $5.9 \pm 1.3^{*}$ \\
\hline MHA & $2.4 \pm 0.2$ & $10.1 \pm 0.9$ & $9.9 \pm 1.1$ & $9.4 \pm 0.9$ & $8.8 \pm 1.3^{\dagger}$ \\
\hline SHA & $2.4 \pm 0.2$ & $9.9 \pm 0.7$ & $9.7 \pm 0.9$ & $9.2 \pm 0.9$ & $7.8 \pm 1.3^{*}$ \\
\hline \multicolumn{6}{|c|}{$\mathrm{PaO}_{2} / \mathrm{FiO}_{2}(\mathrm{mmHg})$} \\
\hline NC & $361.4 \pm 33.3$ & $415.6 \pm 37.1$ & $426.9 \pm 32.7$ & $270.1 \pm 48.8^{*}$ & $179.1 \pm 23.5^{*}$ \\
\hline MHA & $355.3 \pm 39.5$ & $428.6 \pm 36.1^{*}$ & $448.4 \pm 35.9^{*}$ & $432.2 \pm 44.2^{* \dagger}$ & $379.9 \pm 34.5^{\dagger}$ \\
\hline SHA & $350.1 \pm 34.8$ & $456.8 \pm 40.6^{*^{\dagger}}$ & $439.6 \pm 25.2^{*}$ & $388.8 \pm 49.8^{\dagger \#}$ & $298.6 \pm 35.3^{* \dagger \#}$ \\
\hline \multicolumn{6}{|l|}{$\mathrm{pH}$} \\
\hline NC & 7. $42 \pm 0.10$ & 7. $39 \pm 0.03$ & 7. $37 \pm 0.04$ & 7. $32 \pm 0.03^{*}$ & 7. $29 \pm 0.08^{*}$ \\
\hline MHA & 7. $39 \pm 0.08$ & 7. $10 \pm 0.02^{*^{\dagger}}$ & $7.07 \pm 0.04^{*^{\dagger}}$ & $7.07 \pm 0.04^{* \dagger}$ & $7.06 \pm 0.04^{*}$ \\
\hline SHA & $7.37 \pm 0.06$ & $6.94 \pm 0.04^{* \dagger \#}$ & $6.94 \pm 0.03^{* \dagger \#}$ & $6.93 \pm 0.04^{* \dagger \#}$ & $6.93 \pm 0.03^{* \# \#}$ \\
\hline \multicolumn{6}{|c|}{$\mathrm{PaCO}_{2}(\mathrm{mmHg})$} \\
\hline NC & $41.3 \pm 10.1$ & $36.5 \pm 4.0$ & $40.6 \pm 4.8$ & $43.0 \pm 5.2$ & $47.8 \pm 9.6^{*}$ \\
\hline MHA & $38.7 \pm 9.3$ & $88.7 \pm 8.8^{* \dagger}$ & $95.1 \pm 9.9^{* \dagger}$ & $97.0 \pm 9.5^{* \dagger}$ & $93.6 \pm 12.1^{*^{\dagger}}$ \\
\hline SHA & $41.7 \pm 7.3$ & $140.1 \pm 12.6^{* \dagger \#}$ & $141.6 \pm 11.1^{* \dagger \#}$ & $144.2 \pm 14.7^{* \dagger \#}$ & $142.8 \pm 16.7^{* \dagger \#}$ \\
\hline
\end{tabular}

Values are means $\pm S D ; n=16$.

$\mathrm{NC}=$ high-pressure ventilation with a peak inspiratory pressure (PIP) of $30 \mathrm{cmH}_{2} \mathrm{O}$ with normocapnia (inhaled $4-5 \% \mathrm{CO}_{2}$ to maintain $\mathrm{PacO} 2=35-45 \mathrm{mmHg}$ ); $\mathrm{MHA}=\mathrm{NC}$ plus moderate hypercapnic acidosis (inhaled $11-12 \% \mathrm{CO}_{2}$ to maintain $\mathrm{PaCO}_{2}=80-100 \mathrm{mmHg}$ ); $\mathrm{SHA}=\mathrm{NC}$ plus severe hypercapnic acidosis (inhaled $16-17 \%$ CO $\mathrm{CO}_{2}$ to maintain $\mathrm{PaCO}_{2}=130-150 \mathrm{mmHg}$ ); $\mathrm{MAP}=$ systemic mean blood pressures; $\mathrm{HR}=$ heart rates; $\mathrm{PaO}_{2} / \mathrm{FiO}_{2}=$ ratio of arterial oxygen tension to fraction of the inspired oxygen; $\mathrm{PaCO}_{2}=$ arterial carbon dioxide partial pressure; $V_{T}=$ tidal volume.

${ }^{*} p<0.05$ versus baseline except $V_{T}$ (versus $1 \mathrm{~h}$ ); ${ }^{\dagger} p<0.05$ versus NC group; ${ }^{*} p<0.05$ versus MHA group. 

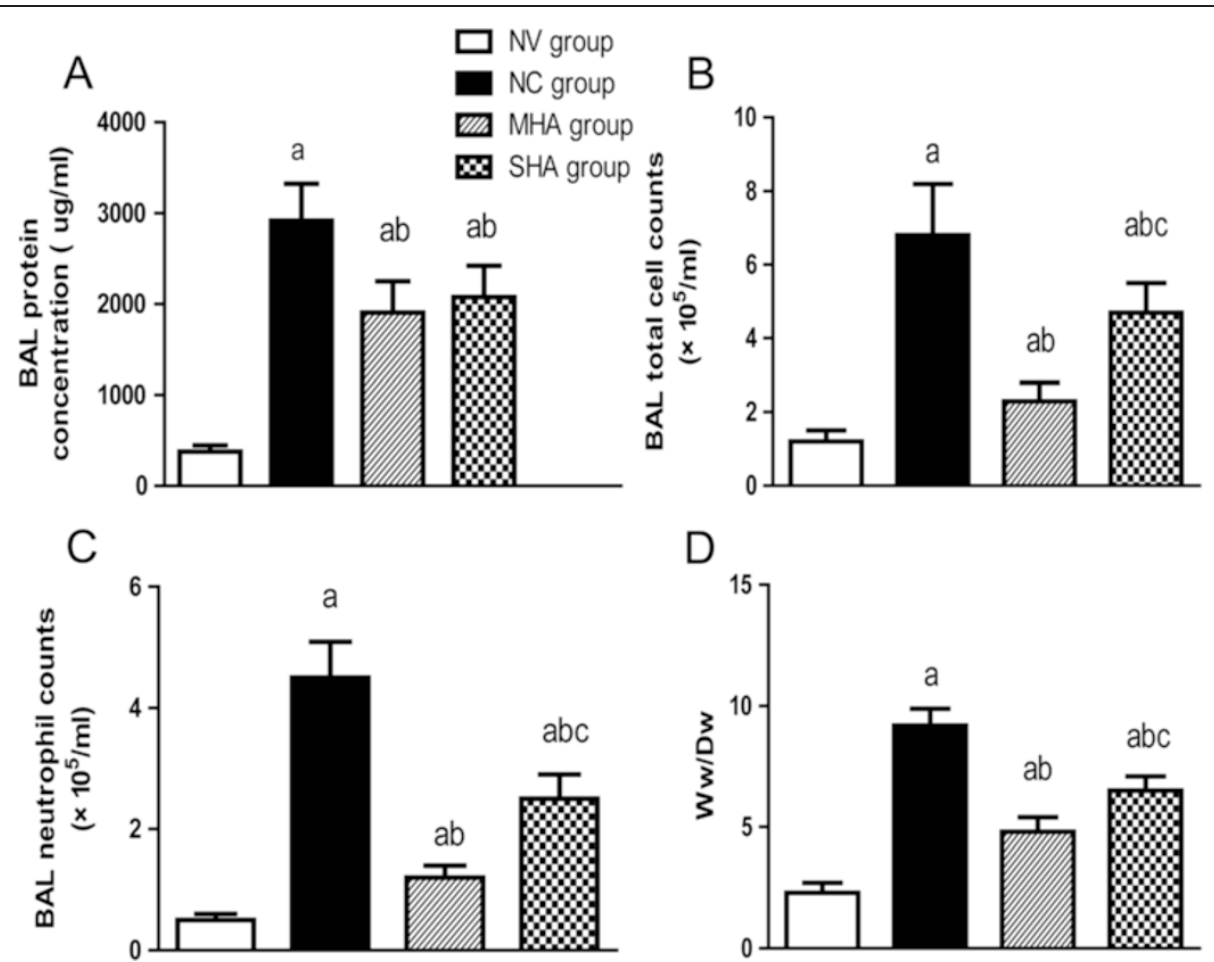

Figure 1 Effect of hypercapnic acidosis on major markers in BALF in rats' lungs induced by high-pressure ventilation (HPV) for $4 \mathrm{~h}$.

(A) Bronchoalveolar lavage fluid (BALF) total protein levels (microgram $/ \mathrm{ml}$ ) were augmented by high-pressure ventilation but diminished by both hypercapnic groups. (B, C) The total and neutrophil cell count in the lavage group increased following HPV but were attenuated in the hypercapnic groups. (D) Pulmonary edema formation was quantified by measuring the wet and desiccated dry weights of the lung tissue. $n=8$ for each group. ${ }^{a} p<0.05$ versus the NV group; ${ }^{b} p<0.05$ versus the NC group; ${ }^{c} p<0.05$ in the SHA group versus the MHA group.

significantly decreased the total cell counts and neutrophil counts at the end of the experiment, and moderate hypercapnic acidosis had a greater effect than severe hypercapnic acidosis.

\section{Cytokines in BALF and myeloperoxidase activity in lung tissues}

The levels of TNF- $\alpha$ and MIP-2 in the BALF were much lower in the NV group, but both significantly increased in the NC group (Table 2, p < 0.05). Hypercapnic acidosis attenuated TNF- $\alpha$ and MIP-2 levels in both HA groups $(\mathrm{p}<0.05)$. After $4 \mathrm{~h}$ of high pressure ventilation, the MHA and SHA groups had decreases in MPO activity of $67 \%$ and $33 \%$, respectively, compared with the NC group (Table 2).

\section{Histology}

Compared with the NV group (Figure 2A), microscopic findings in the lungs from NC rats (Figure 2B) showed moderate to severe edema in the alveolar septum and spaces, hyaline membrane formation. Much less severe changes were present in lungs from both hypercapnic acidosis groups (Figure $2 \mathrm{C}$ and $\mathrm{D}$ ). The lung injury score in the NC group $(11.8 \pm 2.3)$ was higher than that in the $\mathrm{NV}$ group $(2.9 \pm 0.9, \mathrm{P}<0.001)$. SHA group $(7.8 \pm 1.6)$ was lower than the NC group $(\mathrm{P}<0.05)$ but was higher than the MHA group $(4.4 \pm 1.3, \mathrm{P}<0.05)$ (Figure $2 \mathrm{E}$ ).

\section{Lung ICAM-1 expression}

The presence of ICAM-1 as assessed by immunostaining significantly increased in the NC group compared with the normal ventilation group (Figure $3 \mathrm{~A}$ and $\mathrm{B}$ ). Hypercapnic acidosis apparently inhibited ICAM-1 expression (Figure 3A and $B$ ), but significant differences were not observed between the MHA and SHA groups (Figure 3A and B).

Table 2 Comparison of the level of TNF-a, IL-1 $\beta$, and MIP2 in BALF; MPO activity in lungs among groups

\begin{tabular}{lllll}
\hline & NV group & NC group & MHA group & SHA group \\
\hline TNF-a $(\mathrm{pg} / \mathrm{ml})$ & $64 \pm 18$ & $335 \pm 107^{*}$ & $141 \pm 49^{*^{\dagger}}$ & $93 \pm 33^{*^{*}}$ \\
IL-1 $\beta(\mathrm{pg} / \mathrm{ml})$ & $223 \pm 76$ & $1571 \pm 421^{*}$ & $709 \pm 205^{*^{+}}$ & $973 \pm 224^{* \dagger}$ \\
MIP-2 $(\mathrm{pg} / \mathrm{ml})$ & $74 \pm 19$ & $479 \pm 114^{*}$ & $113 \pm 31^{*^{\dagger}}$ & $190 \pm 51^{*+\#}$ \\
MPO $(\mathrm{U} / \mathrm{g})$ & $0.3 \pm 0.1$ & $1.2 \pm 0.4^{*}$ & $0.4 \pm 0.1^{\dagger}$ & $0.8 \pm 0.2^{*+\#}$ \\
\hline
\end{tabular}

Values are means $\pm S D ; n=8$.

$N V=$ normal-pressure ventilation with a peak inspiratory pressure (PIP) of 15 $\mathrm{CmH}_{2} \mathrm{O} ; \mathrm{NC}=$ high-pressure ventilation with a peak inspiratory pressure (PIP) of 30 $\mathrm{CmH}_{2} \mathrm{O} ; \mathrm{MHA}=\mathrm{NC}$ plus moderate hypercapnic acidosis (inhaled $11-12 \% \mathrm{CO}_{2}$ to maintain $\mathrm{PaCO}_{2}=80-100 \mathrm{mmHg}$ ); $\mathrm{SHA}=\mathrm{NC}$ plus severe hypercapnic acidosis (inhaled $16-17 \% \mathrm{CO}_{2}$ to maintain $\mathrm{PaCO}_{2}=130-150 \mathrm{mmHg}$ ); $\mathrm{BALF}$, bronchoalveolar lavage fluid; ${ }^{*} p<0.05$ versus NV group; ${ }^{+} p<0.05$ versus NC group; ${ }^{\#} p<0.05$ versus $M H A$ group. 


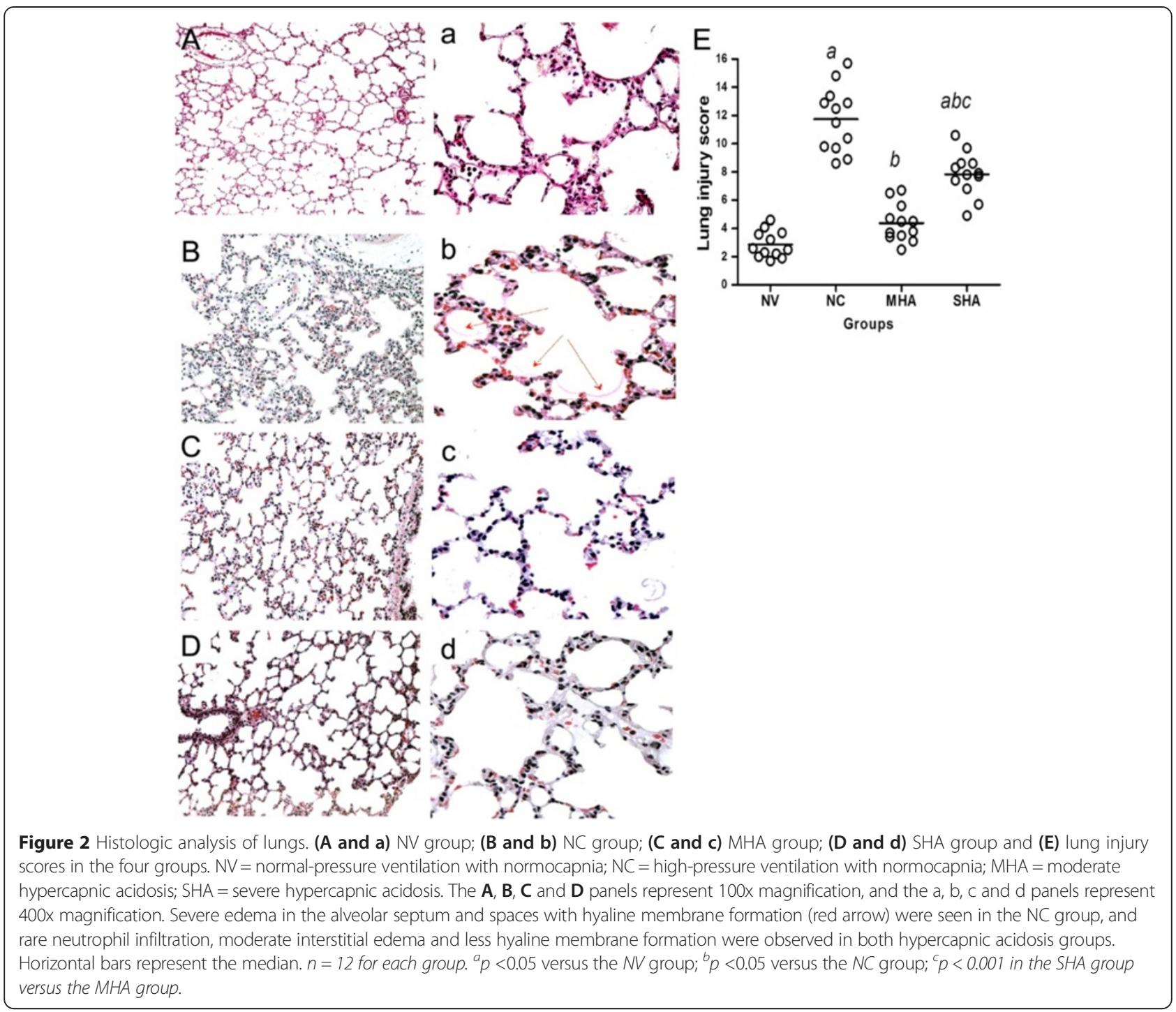

Western blot analysis of ICAM-1 levels also revealed an increase in expression in the NC group compared to sham animals, and a reduction in ICAM-1 was observed in both HA groups (Figure 4A and $\mathrm{C}$ ).

\section{Lung NF-KB expression and IKB- $\alpha$ degradation}

Most NF- $\kappa B$ signals were located in the alveoli and small airway epithelial cells and were mainly expressed in the nucleus (Figure $5 \mathrm{~A}$ and $\mathrm{B}$ ). The expression of NF- $\kappa \mathrm{B}$ in lung tissues was significantly decreased in the HA groups compared with the normal ventilation group (Figure 5C, $\mathrm{P}<0.05$ ). Furthermore, HA significantly reduced total lung tissue NF- $\mathrm{kB}$ activity compared with the normalventilated group as evidenced by the ELISA assay (Figure 5D, $\mathrm{P}<0.05$ ). Western blot analysis for nuclear p65 also revealed an increase in expression in the $\mathrm{NC}$ group and a reduction in both HA groups (Figure $4 \mathrm{~A}$ and $\mathrm{B}$, $\mathrm{P}<0.05)$. With $4 \mathrm{~h}$ of normocapnic HPV, IкB- $\alpha$ protein expression significantly decreased, but levels were relatively higher in both the moderate and severe hypercapnic groups (Figure 4A and D, $\mathrm{P}<0.05$ ).

\section{Discussion}

Our study demonstrates that compared with high $\mathrm{PaCO}_{2}$ (130-150 $\mathrm{mmHg}$ ) ventilation, rats receiving ventilation with a $\mathrm{PaCO}_{2}$ of $80-100 \mathrm{mmHg}$ achieved better oxygenation with fewer histopathologic changes and less inflammatory injury. Furthermore, the hypercapnic acidosis induced by inhalational application of $\mathrm{CO}_{2}$ led to downregulation of NF- $\mathrm{KB}$ activity accompanied by a reduction in lung ICAM-1 expression.

This study was performed using a normal rat lung model, which does not reflect the same pathophysiology observed in humans or in acute respiratory distress syndrome (ARDS) [25]. As we know that the study by Sinclair [13] demonstrated that high tidal volume 


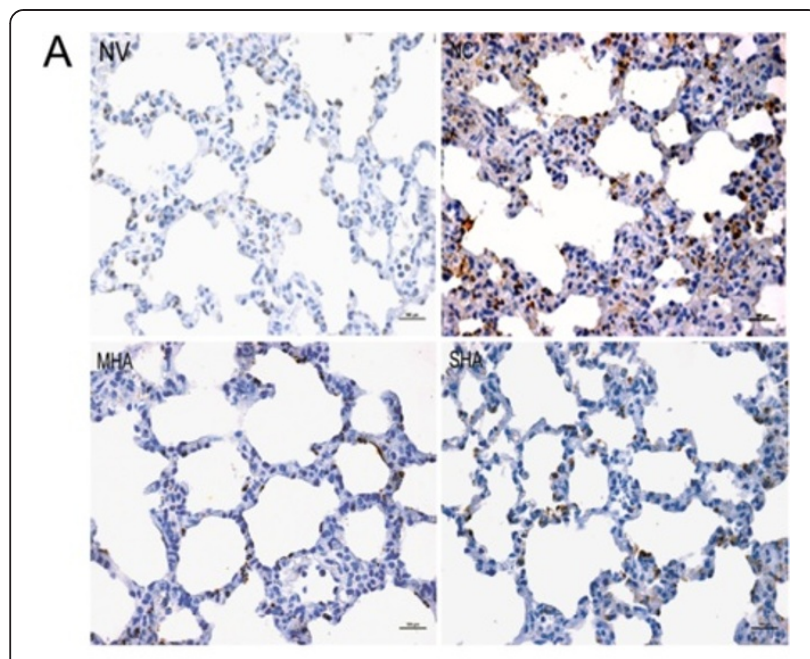

B

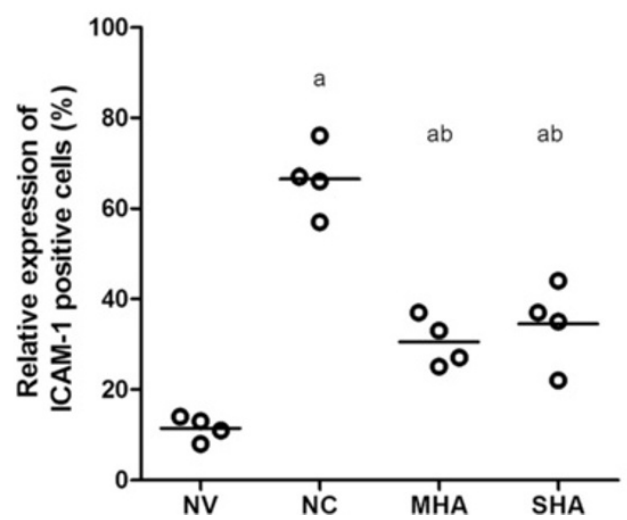

Figure $\mathbf{3}$ Lung immunohistochemistry for ICAM-1 protein expression in lung tissues. NV = normal-pressure ventilation with normocapnia; $\mathrm{NC}=$ high-pressure ventilation with normocapnia; $\mathrm{MHA}=$ moderate hypercapnic acidosis; SHA = severe hypercapnic acidosis (A) Immunohistochemical staining of ICAM-1 in the lung. Sections were stained with a brown DAB color-developing agent and counterstained with hematoxylin. The presence of brown granules in the nucleus was defined as a positive cell. All panels represent a 400x magnification. (B) Scatter plot of ICAM-1-positive (+) cells (\%) in lung tissue. Semi-quantitative analysis of ICAM-1 indicated that hypercapnic acidosis decreased the expression of ICAM-1. Horizontal bars represent the median. $n=4$ for each group. ${ }^{a} p<0.05$ versus the NV group; ${ }^{b} p<0.05$ versus the NC group.

ventilation $(25 \mathrm{cc} / \mathrm{kg})$ for 4 hours produced a peak airway pressure about $33 \mathrm{cmH}_{2} \mathrm{O}$ in eucapnic group, so we chose the high-pressure models used by others to induce VILI [24], which also caused impaired oxygenation and induced an acute lung inflammatory response. Moreover, we only observed the varying levels of $\mathrm{PaCO}_{2}$ and their impact on the development of lung injury induced by high-pressure ventilation, without clouding the results with other potential variables such as $\mathrm{FiO}_{2}$ and PEEP. In the current study, we chose a pressure control mode with $30 \mathrm{cmH}_{2} \mathrm{O}$ PIP ventilation throughout the protocol, $\mathrm{V}_{\mathrm{T}}$ decreased along with the development of lung injury and impaired oxygenation while $\mathrm{PaCO}_{2}$ increased correspondingly. Thus, this could reflect the same pathophysiology observed in the others research regarding VILI. Moreover, our study showed that acute hypercapnic acidosis was well-tolerated as long as perfusion and arterial oxygenation were maintained in the hypercapnic acidosis groups. This result likely occurred because inhaled $\mathrm{CO}_{2}$ improves gas exchange and ventilation-perfusion ratio matching [26] by reducing the heterogeneity of the pulmonary blood flow distribution and accordingly generates a higher $\mathrm{PaO}_{2}[27,28]$.

$\mathrm{NF}-\mathrm{kB}$ is a key transcription factor in modulating various inflammatory genes including TNF-a, IL-1 $\beta$ and adhesion molecules. NF- $\mathrm{kB}$ activation also activates neutrophils accumulating in the lung tissue of ALI models [29-31]. However, even low-tidal volume ventilation activates inflammation (30). A study that looks at NF- $\mathrm{kB}$ translocation after VILI, and its down-regulation by NF- $\mathrm{B}$, it needs to demonstrate that this is a high stretch phenomenon, and does not occur with low stretch mechanical ventilation in the model also. Thus, we have a control group of animals who are either subject to normal pressure ventilation for four hours, or sham anaesthetized and non-ventilated animals. After $4 \mathrm{~h}$ of $\mathrm{HPV}$, we found that NF-kB was mostly expressed in alveoli and small airway epithelial cells receiving only HPV. This observation was verified with an ELISA and western blot, both of which demonstrated that the NF- $k B$ pathway in the lung tissue was markedly inhibited by hypercapnic acidosis. In the cytoplasm, the $I-\kappa B$ degradation prompts NF- $\kappa B$ to transfer into the nucleus, where it acts as a transcription factor regulating the expression of inflammatory mediators (TNF- $\alpha$ and IL-1 $\beta$, etc.). These factors can be partially reversed by hypercapnic acidosis, which reveals that NF- $\mathrm{kB}$ should be an important factor in the process. Previous reports showed that hypercapnic acidosis reduced the severity of both mild and severe VILI by reducing NF- $\mathrm{kB}$ activation via a decrease in the breakdown of cytosolic I- $\mathrm{KB}$ inhibitory proteins; in vitro studies provided further support for this mechanism of action of hypercapnic acidosis [12]. However, our in vivo study found that $\mathrm{HA}$ abolished the decrease in densitometric lung tissue cytoplasmic $I \kappa B \alpha$ concentrations induced by HPV. HA also inhibited HPV-induced up-regulation of the expression of ICAM-1 and MPO activity. Furthermore, Cummins also demonstrated reversible IKK- $\alpha$ nuclear localization in a $\mathrm{CO}_{2}$-dependent manner over a range of physiologic $\mathrm{CO}_{2}$ concentrations that was associated with an attenuation of LPS-induced NF- $\kappa B$ signaling and target-gene expression. This finding is consistent with $\mathrm{CO}_{2}$ affecting IKK- $\alpha$ and contributing to the attenuation of inflammation [32]. However, it is unclear whether $\mathrm{CO}_{2}$ - or $\mathrm{pH}$-mediated anti-inflammatory mechanisms 


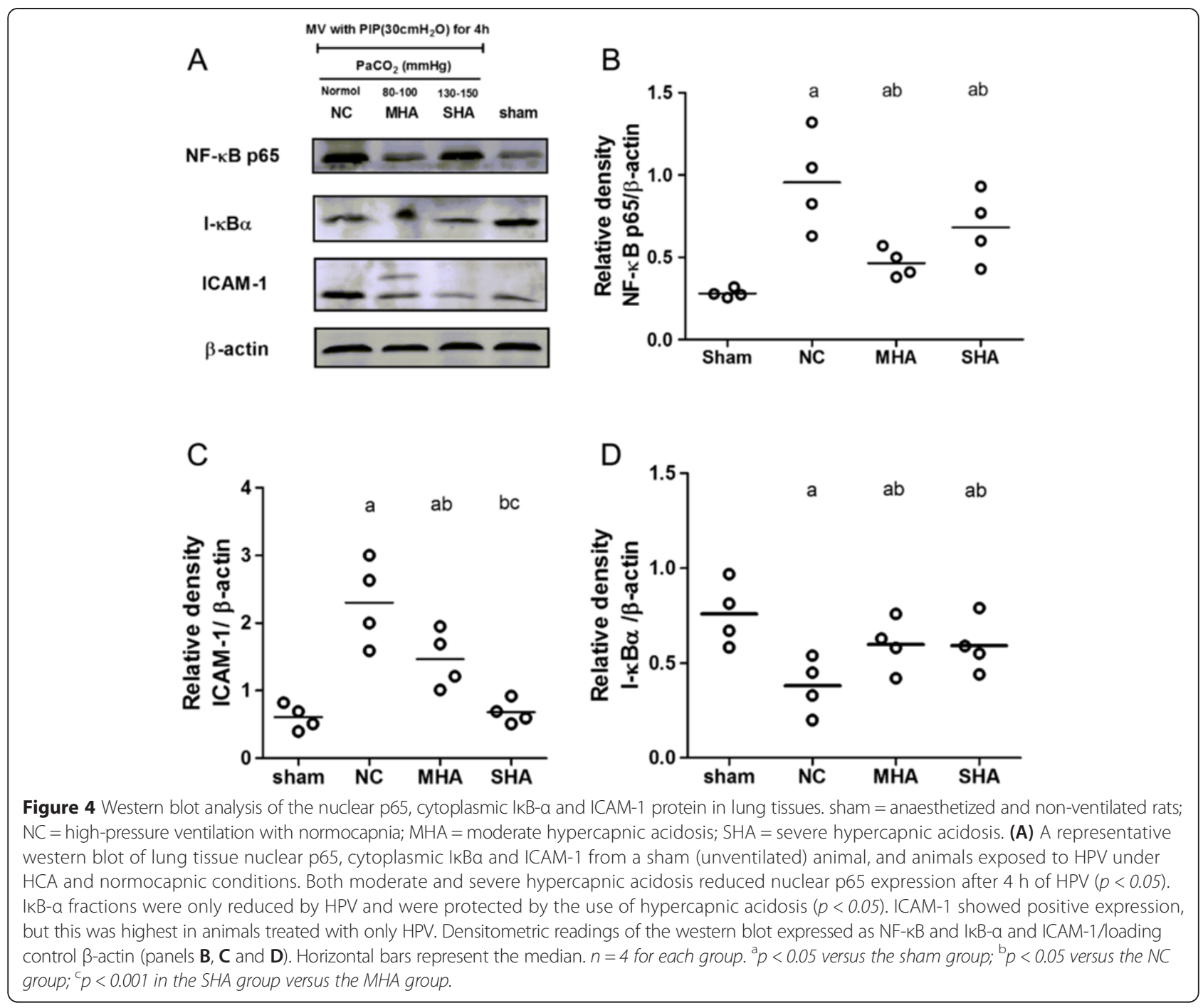

contribute to lung protection in therapeutic hypercapnia. One study demonstrates that hypercapnia inhibits the release of interleukin-8 from stimulated leukocytes; such inhibition appears to be based on increased intracellular $\mathrm{H}^{+}$and dependent on intracellular carbonic anhydrase [33]. These results suggest that the effects of hypercapnic acidosis on the NF-kB pathway may be complex and dependent on the milieu of unstable intermediates created by the interactions between hydrogen ions and $\mathrm{CO}_{2}$.

Although moderate hypercapnic acidosis is commonly observed when using protective ventilator strategies in experimental animal settings, our report is the first study on the effect of greater $\mathrm{CO}_{2}$ "doses" on VILI to our knowledge. Previous studies have shown that prophylactic maintenance of inhaled $\mathrm{CO}_{2}$ (12-25\%) to maintain $\mathrm{PaCO}_{2}$ at a level of $80-100 \mathrm{mmHg}$ reduced ischemia-reperfusion injury $[5,22]$ and VILI $[11,13]$. However, whether a $\mathrm{PaCO}_{2}$ of $100 \mathrm{mmHg}$ is the upper limit of the protective range of hypercapnia in VILI remains unknown. In the current study, although severe hypercapnic acidosis $\left(\mathrm{PaCO}_{2}\right.$ at $\left.130-150 \mathrm{mmHg}\right)$ attenuated the severity of VILI, with prolonged ventilation until the end of the protocol, the oxygenation and histopathologic changes were progressively worse compared with moderate hypercapnic acidosis $\left(\mathrm{PaCO}_{2}\right.$ at $\left.80-100 \mathrm{mmHg}\right)$. The protective effects of hypercapnia may be offset by a potential for adverse effects at higher levels. This possibility is supported by previous animal studies suggesting that protection from the adverse effects of brain ischemia was superior when the inhaled $\mathrm{CO}_{2}$ was kept at $6 \%$ rather than at 9\% [34]. Of importance, severe hypercapnia induced by inhaling $15 \%$ $\mathrm{CO}_{2}$ has been proven to aggravate neurologic injury [35]. Furthermore, acute elevations in $\mathrm{PaCO}_{2}$ may induce intracellular acidosis and result in cardiovascular compromise, muscle weakness, increased intracranial pressure and central nervous system dysfunction [36]. It is obvious that 


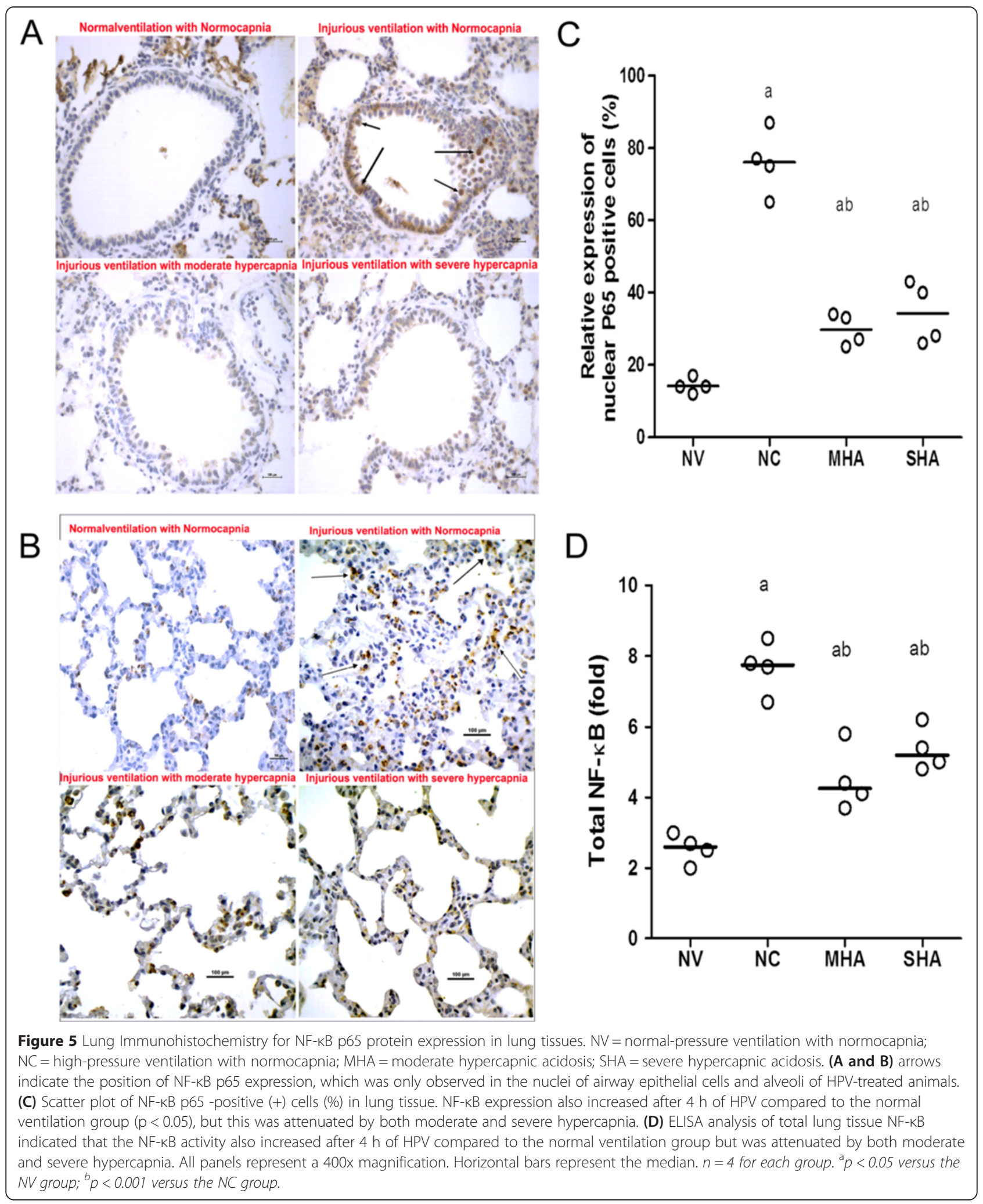

acidosis is a double-edged sword that may be difficult to apply in critically ill patients. Nevertheless, the results of our study show that induction of HA by the addition of carbon dioxide to the inspired gas may necessitate attention to the potential for adverse effects at higher levels of $\mathrm{PaCO}_{2}$ in patients with ARDS during mechanical ventilation. On 
the other hand, our studies must be viewed as hypothesisgenerating and should be tested by intensive studies in preclinical models.

Despite its interesting results, this exploratory study was limited in several ways. First, the animals were anesthetized with an intraperitoneal injection of pentobarbital sodium alone, which may not have reached the depth of anesthesia corresponding to clinical practice. Further studies should avoid this inappropriate anesthesia. Second, the pulmonary vasoconstriction and lung mechanics (i.e., plateau pressures, compliance, etc.) were not measured, which limited the interpretation of the specific effects of hypercapnic acidosis on pulmonary and systemic hemodynamic parameters. Third, the duration of the ALI models was limited to $4 \mathrm{~h}$ of mechanical ventilation and was too short to extrapolate to clinical practice. The results indicate that it is reasonable to believe that the acidosis generated by acute hypercapnia may be an important factor in acute models of VILI. Further study should be performed to evaluate the effects of hypercapnia in ALI models of considerably longer duration.

\section{Conclusion}

This study demonstrates that an increased level of carbon dioxide has a protective effect against VILI in rats. Animals exposed to moderate hypercapnia $\left(\mathrm{a} \mathrm{PaCO}_{2}\right.$ of $80-100 \mathrm{mmHg}$ ) remained in a more favorable condition and had less histopathologic changes and inflammatory injury than animals with severe hypercapnia $\left(\mathrm{a} \mathrm{PaCO}_{2}\right.$ of $130-150 \mathrm{mmHg}$ ). The protective mechanism is likely associated with the inhibition of NF- $\mathrm{kB}$ expression during high pressure stretch.

\section{Competing interests}

The authors declare that they have no competing interests.

\section{Authors' contributions}

$W Y$ and ZY participated in the design of the study and the experiments, were involved in the data extraction and the statistical analysis, and drafted the manuscript. XC and YG participated in the design of the study and in experiments and helped draft the manuscript. $\mathrm{LZ}$ and $\mathrm{HZ}$ participated in the design of the study and in the experiments. WL participated in the design of the study, was involved in the interpretation of the results, and helped draft the manuscript. All authors read and approved the final manuscript for publication.

\section{Acknowledgments}

This study was supported by the graduate (2012RFXXS064) and (2014RFQGJ113) from the Harbin Science and Technology Commission Foundation.

\section{Author details}

'Department of Anesthesiology, Second Affiliated Hospital of Harbin Medical University; Anesthesiology Key Laboratory, Harbin Medical University, Harbin 150086, China. ${ }^{2}$ Education Department of Heilongjiang Province, Anesthesiology Key Laboratory, Harbin Medical University, Harbin, Heilongjiang Province, China.

Received: 6 August 2014 Accepted: 22 April 2015

Published online: 30 April 2015

\section{References}

1. Dreyfuss D, Basset G, Soler P, Saumon G. Intermittent positive-pressure hyperventilation with high inflation pressures produces pulmonary microvascular injury in rats. Am Rev Respir Dis. 1985:132(4):880-4.

2. Dreyfuss D, Saumon G. Ventilator-induced lung injury: lessons from experimental studies. Am J Respir Crit Care Med. 1998;157(1):294-323.

3. Amato MB, Barbas CS, Medeiros DM, Magaldi RB, Schettino GP, Lorenzi-Filho G, et al. Effect of a protective-ventilation strategy on mortality in the acute respiratory distress syndrome. N Engl J Med. 1998;338(6):347-54.

4. Maeda YFY, Uchiyama A, Matsuura N, Mashimo T, Nishimura M. Effects of peak inspiratory flow on development of ventilator-induced lung injury in rabbits. Anesthesiology. 2004;101(3):722-8.

5. Laffey JGTM, Engelberts D, Luo X, Yuan S, Keith Tanswell A, Post M, et al. Therapeutic hypercapnia reduces pulmonary and systemic injury following in vivo lung reperfusion. Am J Respir Crit Care Med. 2000;162(6):2287-94.

6. Shibata KCN, Engelberts D, Takeuchi A, Fedorko L, Kavanagh BP. Hypercapnic acidosis may attenuate acute lung injury by inhibition of endogenous xanthine oxidase. Am J Respir Crit Care Med. 1998;158(5 Pt 1):1578-84

7. Laffey JGHD, Hopkins N, Hyvelin JM, Boylan JF, McLoughlin P. Hypercapnic acidosis attenuates endotoxin-induced acute lung injury. Am J Respir Crit Care Med. 2004;169(1):46-56.

8. Nichol AD, O'Cronin DF, Naughton F, Hopkins N, Boylan J, McLoughlin P. Hypercapnic acidosis reduces oxidative reactions in endotoxin-induced lung injury. Anesthesiol. 2010;113(1):116-25

9. Costello J, Higgins B, Contreras M, Chonghaile MN, Hassett P, O'Toole D, et al. Hypercapnic acidosis attenuates shock and lung injury in early and prolonged systemic sepsis. Crit Care Med. 2009;37(8):2412-20.

10. Higgins BD, Costello J, Contreras M, Hassett P, OToole D, Laffey JG. Differential effects of buffered hypercapnia versus hypercapnic acidosis on shock and lung injury induced by systemic sepsis. Anesthesiol. 2009;111(6):1317-26.

11. Broccard AFHJ, Vannay C, Markert M, Sauty A, Feihl F, Schaller MD. Protective effects of hypercapnic acidosis on ventilator-induced lung injury. Am J Respir Crit Care Med. 2001;164(5):802-6.

12. Contreras M, Ansari B, Curley G, Higgins BD, Hassett P, O'Toole D, et al. Hypercapnic acidosis attenuates ventilation-induced lung injury by a nuclear factor-kappaB-dependent mechanism. Crit Care Med. 2012;40(9):2622-30.

13. Sinclair SEKD, Lamm WJ, Starr IR, Chi EY, Hlastala MP. Hypercapnic acidosis is protective in an in vivo model of ventilator-induced lung injury. Am J Respir Crit Care Med. 2002:166(3):403-8.

14. Peltekova V, Engelberts D, Otulakowski G, Uematsu S, Post M, Kavanagh BP. Hypercapnic acidosis in ventilator-induced lung injury. Intensive Care Med. 2010;36(5):869-78.

15. Laffey JGED, Duggan M, Veldhuizen R, Lewis JF, Kavanagh BP. Carbon dioxide attenuates pulmonary impairment resulting from hyperventilation. Crit Care Med. 2003;31(11):2634-40.

16. Kregenow DA, Swenson ER. The lung and carbon dioxide: implications for permissive and therapeutic hypercapnia. Eur Respir J. 2002;20(1):6-11.

17. Blackwell TS, Christman JW. The role of nuclear factor-kappa B in cytokine gene regulation. Am J Respir Cell Mol Biol. 1997;17(1):3-9.

18. Christman JW, Lancaster LH, Blackwell TS. Nuclear factor kappa B: a pivotal role in the systemic inflammatory response syndrome and new target for therapy. Intensive Care Med. 1998;24(11):1131-8.

19. Chen LW, Egan L, Li ZW, Greten FR, Kagnoff MF, Karin M. The two faces of IKK and NF-kappaB inhibition: prevention of systemic inflammation but increased local injury following intestinal ischemia-reperfusion. Nat Med. 2003;9(5):575-81.

20. OToole D, Hassett P, Contreras M, Higgins BD, McKeown ST, McAuley DF, et al. Hypercapnic acidosis attenuates pulmonary epithelial wound repair by an NF-kappaB dependent mechanism. Thorax. 2009;64(11):976-82.

21. Yang WC, Song CY, Wang N, Zhang LL, Yue ZY, Cui XG, et al. Hypercapnic acidosis confers antioxidant and anti-apoptosis effects against ventilator-induced lung injury. Lab Invest. 2013;93(12):1339-49.

22. Laffey JGJR, Engelberts D, Tanswell AK, Post M, Lindsay T, Mullen JB, et al. Effects of therapeutic hypercapnia on mesenteric ischemia-reperfusion injury. Am J Respir Crit Care Med. 2003;168(11):1383-90.

23. Zhou Q, Cao B, Niu L, Cui X, Yu H, Liu J, et al. Effects of permissive hypercapnia on transient global cerebral ischemia-reperfusion injury in rats. Anesthesiol. 2010;112(2):288-97. 
24. Imanaka H, Shimaoka M, Matsuura N, Nishimura M, Ohta N, Kiyono H. Ventilator-induced lung injury is associated with neutrophil infiltration, macrophage activation, and TGF-beta 1 mRNA upregulation in rat lungs. Anesth Analg. 2001;92(2):428-36.

25. Gattinoni L, Pesenti A, Avalli L, Rossi F, Bombino M. Pressure-volume curve of total respiratory system in acute respiratory failure. Computed tomographic scan study. Am Rev Respir Dis. 1987;136(3):730-6.

26. Sinclair SE, Kregenow DA, Starr I, Schimmel C, Lamm WJ, Hlastala MP, et al. Therapeutic hypercapnia and ventilation-perfusion matching in acute lung injury: low minute ventilation vs inspired CO2. Chest. 2006;130(1):85-92.

27. Brogan TV, Hedges RG, McKinney S, Robertson HT, Hlastala MP, Swenson ER. Pulmonary NO synthase inhibition and inspired CO2: effects on $\mathrm{V}^{\prime} / \mathrm{Q}^{\prime}$ and pulmonary blood flow distribution. Eur Respir J. 2000;16(2):288-95.

28. Akca O, Doufas AG, Morioka N, Iscoe S, Fisher J, Sessler DI. Hypercapnia improves tissue oxygenation. Anesthesiol. 2002;97(4):801-6.

29. Liu SF, Ye X, Malik AB. Inhibition of NF-kappaB activation by pyrrolidine dithiocarbamate prevents In vivo expression of proinflammatory genes. Circ. 1999;100(12):1330-7.

30. Schwartz MD, Moore EE, Moore FA, Shenkar R, Moine P, Haenel JB, et al. Nuclear factor-kappa B is activated in alveolar macrophages from patients with acute respiratory distress syndrome. Crit Care Med. 1996;24(8):1285-92.

31. Blackwell TS, Blackwell TR, Holden EP, Christman BW, Christman JW. In vivo antioxidant treatment suppresses nuclear factor-kappa B activation and neutrophilic lung inflammation. J Immunol. 1996;157(4):1630-7.

32. Cummins EP, Oliver KM, Lenihan CR, Fitzpatrick SF, Bruning U, Scholz CC, et al. NF-kappaB links CO2 sensing to innate immunity and inflammation in mammalian cells. J Immunol. 2010;185(7):4439-45.

33. Coakley RJ, Taggart C, Greene C, McElvaney NG, O'Neill SJ. Ambient pCO2 modulates intracellular $\mathrm{pH}$, intracellular oxidant generation, and interleukin-8 secretion in human neutrophils. J Leukoc Biol. 2002;71(4):603-10.

34. Vannucci RC, Towfighi J, Heitjan DF, Brucklacher RM. Carbon dioxide protects the perinatal brain from hypoxic-ischemic damage: an experimental study in the immature rat. Pediatr. 1995;95(6):868-74.

35. Vannucci RC, Towfighi J, Brucklacher RM, Vannucci SJ. Effect of extreme hypercapnia on hypoxic-ischemic brain damage in the immature rat. Pediatr Res. 2001;49(6):799-803.

36. Marini JJ. Pressure-targeted, lung-protective ventilatory support in acute lung injury. Chest. 1994;105(3 Suppl):109S-15.

\section{Submit your next manuscript to BioMed Central and take full advantage of:}

- Convenient online submission

- Thorough peer review

- No space constraints or color figure charges

- Immediate publication on acceptance

- Inclusion in PubMed, CAS, Scopus and Google Scholar

- Research which is freely available for redistribution

Submit your manuscript at www.biomedcentral.com/submit 